\title{
Cloud-Based E-Learning: A Proposed Model and Benefits by Using E-Learning Based on Cloud Computing for Educational Institution
}

\author{
Nungki Selviandro and Zainal Arifin Hasibuan \\ Digital Library and Distance Learning Laboratory \\ Faculty of Computer Science Universitas Indonesia \\ nungki.selviandro@ui.ac.id, zhasibua@cs.ui.ac.id
}

\begin{abstract}
The increasing research in the areas of information technology have a positive impact in the world of education. The implementation of e-learning is one of contribution from information technology to the world of education. The implementation of e-learning has been implemented by several educational institutions in Indonesia. E-Learning provides many benefits such as flexibility, diversity, measurement, and so on. The current e-learning applications required large investments in infrastructure systems regardless of commercial or open source e-learning application. If the institution tended to use open source elearning application it would need more cost to hire professional staff to maintain and upgrade the e-learning application. It can be challenging to implement e-learning in educational institutions. Another problem that can arise in the use of e-laerning trend today is more likely to institution building their own elearning system itself. If two or more institutions are willing to build and use an e-learning so they can minimize the expenditure to develop the system and share learning materials more likely happened. This paper discuss the current state and challenges in e-learning and then explained the basic concept and previous proposed architectures of cloud computing. In this paper authors also proposed a model of cloud-based e-learning that consists of five layer, namely: (1) infrastructure layer; (2) platform layer; (3) application layer; (4) access layer; and (5) user layer. In addition to this paper we also illustrated the shift paradigm from conventional e-learning to cloud-based e-learning and described the expected benefits by using cloud-based e-learning.
\end{abstract}

Keywords: E-Learning, Cloud Computing, Cloud-Based E-Learning.

\section{Introduction}

Nowadays e-learning widely use by educational institutions for supporting their learning process and provide anytime service for learners to access learning material and information. The implementation of e-learning has been implemented by several educational institutions in Indonesia. E-Learning provides many benefits such as flexibility, diversity, measurement, and others [11], even though its implementation still exist many difficulties. The main problem experienced when to start applying e-learning is 
the high initial cost or in other words is the economic factor [2]. It is becoming a major focus for the institutions that will implementing e-learning. Institutions are categorized as low budget certainly be very difficult to implement e-learning, even if the institution has an adequate budget also expects a minimal budget that can be spent to implement e-learning. The inadequate infrastructure becomes a major problem in the implementation of e-learning. Institutions that want to implement e-learning difficulties in the procurement of server/PC, storage, and network [3]. Besides provide infrastructure The next issue is human resources, not all of the institutions have the professional staff for designing, developing systems to manage e-learning, in addition to the growing applying of e-learning as well is required expert in designing teaching materials commonly known as the instructional designer. It is also a consideration in the implementation of e-learning for each institution to implement it. Because institutions will also estimate the cost to employ them in order to provide specifically for elearning systems.

Along with the development of the IT world, cloud computing is gradually become the new paradigm of innovation in the IT world, cloud computing is a computing services that can be used through the Internet in accordance with the needs of users with little interaction between service providers and users. Cloud computing technology as well described as a computing resource that provides a highly scalable as external services through the Internet. Therefore, cloud computing can be considered as an alternative to minimize the cost of infrastructure and human resources for development and maintenance process of e-learning systems [4].

In this paper the author will discuss the current state and challenges of e-learning as well as basic concepts of cloud cover and the implementation of the service model, and the author will discuss some of the architecture of cloud-based e-learning that has been proposed by previous researchers. In addition the author will introduce the model proposed in the implementation of e-learning in the cloud environment as an alternative to conventional e-learning implementations are widely used in educational institutions today. The author will also explain the expected benefit by adopting the model of cloud-based e-learning.

\section{E-Learning: Current State and Challenges}

E-Learning is an internet-based learning process which aims to support conventional learning process that using internet technology and will not replace traditional education method [11]. Usually, e-learning systems are based on client-server architecure and web-based technology [17]. This architecture has some limitation so that e-learning can not be used to its full potential, because has some limitation such as lack of interoperability and accessibility. Based on previous study, in order to solve interoperability issue, the use of web services has been implemented by several previous researchers as practiced by Grewal et al. (2005), Pankratius et al. (2004), Xu et al. (2003). The using of web service has successfully answered the issue of interoperability from e-learning with focusing on selecting and combining the learning objects [5]. 
With the development of mobile technology make e-learning is increasingly being used. The use of mobile technology in the implementation of e-learning is commonly known as mobile learning. There are many definitions of mobile learning, one of which is mobile learning defined by Lan \& Sie (2010) as a learning model that enables participants to achieve the teaching learning materials anywhere and anytime using mobile technology and the internet. This definition may mean that mobile learning could include mobile phones, smartphones, personal digital assistants (PDAs) and their peripherals. Using mobile learning can help address the issue of accessibility in accessing the e-learning system.

Nowadays the use of e-learning applications can be based on commercial products or from open source. The advantage of using commercial products are the implementation time is quick due to technical support from the vendor and there will be ongoing maintenance cost. The disadvantage of using commercial e-learning applications are the initial cost of procuring commercial e-learning software is very high and there will the cost of insfrastructure [4]. Open source e-learning applications widely used in university. The initial cost of e-learning software is very low, but there still need expensive investment for the infrastructure and need more cost to hire professional staff for maintaining and upgrading the e-learning applications.

Based on the above phenomenon, the current e-learning applications required large investments in infrastructure systems regardless of commercial or open source. If the institution tended to use open source e-learning application it would need more cost to hire professional staff to maintain and enhance the e-learning application. It can be challenging to implement e-learning in educational institutions. Another problem that can arise in the use of e-laerning trend today is more likely to institution building their own e-learning system itself. If two or more institutions are willing to build and use an e-learning so they can minimize the expenditure to develop the system and share learning materials more likely happened.

\section{Cloud Computing}

Cloud Computing is a new paradigm to organize and manage ICT resources. There are various definitions of cloud computing, one of which is the definition according to The National Institute of Standards and Technology (NIST) which defines cloud computing as "model for enabling convenient, on-demand network access to a shared pool of configurable computing resources (e.g., networks, servers, storage, applications, and services) that can be rapidly provisioned and released with minimal management effort or service provider interaction" [22]. Generally speaking, the cloud computing service model consists of three layers [5], among others: (1) Software as a Service (SaaS); (2) Platform as a service (PaaS); (3) Infrastructure as a service (IaaS) [6]. 


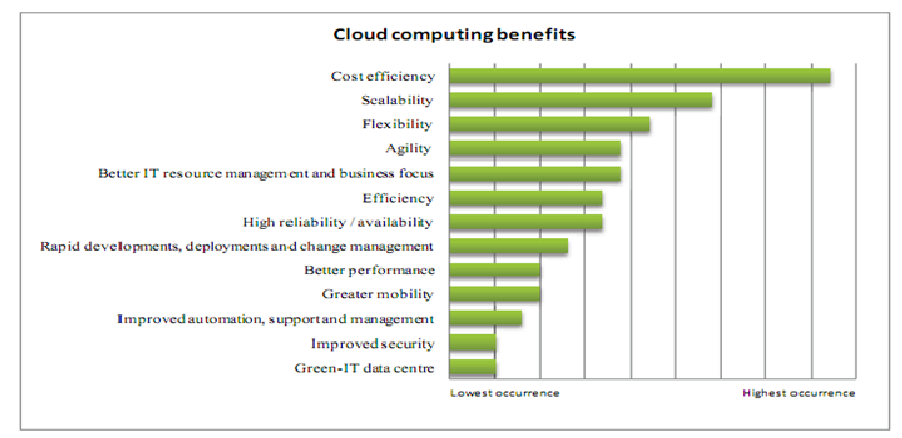

Fig. 1. The Advantages of implementing Cloud Computing [8]

In practice, cloud computing has four implementation models where each model has certain characteristics [7], among others: (1) Private, the model is aimed at an organization where cloud operations are managed by a third party or the organization itself; (2) Public, service on this model is intended for the general public or the industry in which the various services provided by the cloud computing service provider organization (3) Community, this model is managed by several organizations that form a community of practice in which the operations are managed by the community with the division of tasks particular; (4) Hybrid, this model is a combination of various models existing cloud distribution. Typically, this is done with a combination of specific purposes where there is an attachment for example: technological standards and data ownership.

The implementation of cloud computing is growing due to have advantages such as that illustrated in Figure 1, it can be seen that the efficiency cost is a major indicator of the advantages possessed by Cloud Computing. Cost efficiency can be realized due to several components such as the cost of financing the purchase of infrastructure and application development and operational expenses (management fees and maintenance) can be reduced. Cloud Computing on the implementation can be categorized two types, namely free service or pay per use (pay-as-you-go services) [12], users will only be charged when using services from providers the service.

\section{Cloud-Based E-Learning Architecture}

In this chapter will discussed about the previous cloud-based architecture that developed by former researcher in this area and also the proposed cloud-based e-learning archictecture from this paper. In addition for this chapter also will be discussed the contribution from the proposed architecture. 


\subsection{Previous Cloud-Based E-Learning Architecture}

The research of e-learning in the cloud environment have been carried out by previous researchers, such as those conducted by Chuang, Chang, and Sung (2011), Dong et al (2009), Vishwakarma \& Narayanan (2011), Pocatilu (2010) and Ghazizadeh (2012). Research on the application of e-learning in a cloud environment is one form of cloud services education services. There are several architectural cloud-based e-learning have been proposed by previous researcher. In this paper will discuss three architectural cloud-based e-learning, such as architecture proposed by Phankokkruad (2012), Wang, Pai, \& Yen (2011), and Masud \& Huang (2012).

Phankokkruad (2012) proposed e-learning architecture based on cloud computing consists of three layers: (1) infrastructure layer, (2) platform (middle) layer, and, (3) application layer. Infrastructure layer is a hardware layer that supplies the computing and storage capacity for the higher level and this layer, which is used as e-learning and software virtualization tehcnologies, ensures the stability and reliability of the infrastructure. The second layer is Platform layer, this layer is a middle layer consisting middleware that is Web service. It is used for providing the learning resources as a service. This layer consists of two modules: item classification module (ICM) and course selection module (CSM). They are used for accessing the items from the item bank and selecting suitable learning content from the content database. The third layer is Application layer which is responsible for interface provision for the students.

Not much difference can be inferred from the comparison of the architecture delivered by Phankokkruad (2012) and Wang, Pai, \& Yen (2011). They proposed an architecture of e-learning-based cloud computing consists of three layers, namely: (1) infrastructure layer, (2) middleware layer, and, (3) application layer.

The first layer is infrastructure layer. It is employed as the e-learning resource pool that consists of hardware and software virtualization technologies to ensure the stablility and reliability of the infrastructure. This layer also supplies the computing and storage capacity for the higher level. The second layer is middleware layer. It focuses in providing a sharable platform consisting of two modules: CNRI's (Corporation for National Research Initiatives) Handler System Module and Metadata Transformation System Module. The final layer is application layer. At this layer, cloud computing provides convenient access to the e-learning resources.

The next architecture proposed by Masud \& Huang (2012) consists of five layers. The First layer is infrastructure layer. It is composed of information infrastructure and teaching resources. Information infrastructure contains internet/intranet, system software, information management system and some common hardware. Teaching resources stored up mainly in traditional teaching model and distributed in different departments and domain. The second layer is software resource layer. This layer is composed by operating system and middleware. A variety of software resources are integrated through middleware technology to provide a unified interface for software developers to develop applications and embed them in the cloud. The third layer is resource management layer. In order to effectuate on demand free flow and distribution of software over various hardware resources, this layer utilizes integration of virtualization and cloud computing scheduling strategy. The fourth layer is service 
layer. This layer has three levels of services namely, SaaS, PaaS, and IaaS. In SaaS, cloud computing service is provided to customers, contrasting to traditional software, cloud customers use software via the internet without any need to purchase, maintain, and upgrade. They simply to pay a monthly fee. The last layer is application layer. This layer is a specific layer consisting of applications of integrated teaching resources, including interactive courses and the teaching resources sharing. The teaching resources include teaching material, teaching information, as well as the full sharing human resources.

\subsection{Proposed Cloud-Based E-Learning Architecture}

In this paper we propose the architecture that we have designed by modifying previous architectures that we used as references. Our proposed architecture consists of five layers (as shown in Figure 5), namely: (1) infrastructure layer; (2) platform layer; (3) application layer; (4) access layer; and (5) user layer.

First layer is infrastructure layer. This layer contains architecture supporting infrastructure, such as: Cloud platform, virtual machine, virtual repositories and physical infrastructure such as servers, network devices, storage, buildings and other physical facilities. The infrastrucuter layer shares IT infrstructure resources and connects the system huge system pool together to provide services. Cloud computing enable the hardware layer to run more like the internet, to make the hardware resources shared and accessed the data resources in secure and scalable way. The second layer is platform layer. In this layer running the operating system where e-learning application will be running. Besides the operating system, this layer also consists of variety of software that support the application layer so that it can run properly. The third layer

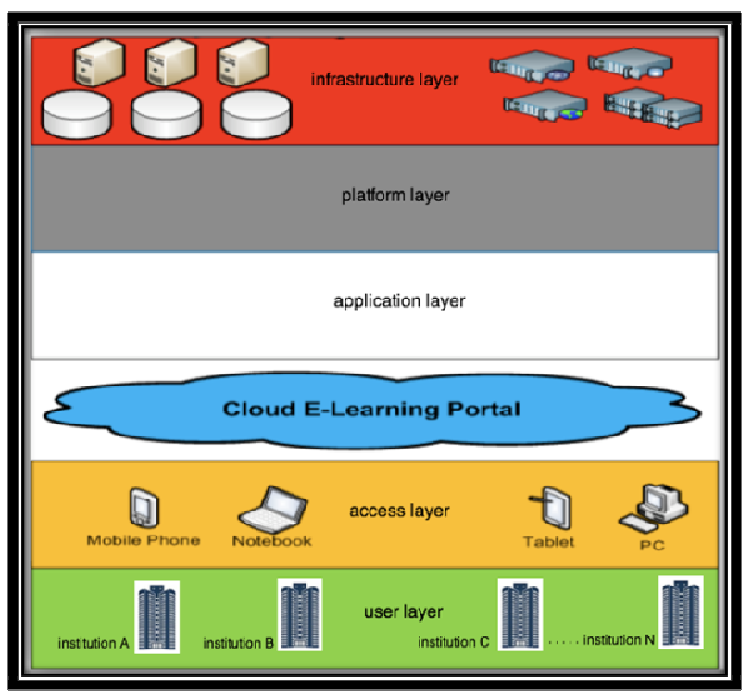

Fig. 2. Proposed Cloud E-Learning Architecture 
is application layer. This layer is a specific e-learning application that is utilized for sharing learning resources and interaction among users that includes synchronous or asynchronous discussion and chatting. We added the access layer in our architecture. This access layer is the fourth layer in our proposed architecture. This layer is in charge of managing access to cloud e-learning services which is available on the architecture such as: types of access devices and presentation models. This study adopts the concept of multi-channel access which enables a variety of available services that accessible through a variety of devices (such as mobile phones, smartphones, computer, etc.) and a variety of presentation models (such as mobile applications, desktop applications, and others) [21]. The purpose of the adoption of this concept is to increase the availability of devices that access the cloud service e-learning can be found in the architecture used untrammeled access devices. Besides the addition of the access layer, the architecture we propose the user layer consists of various educational institutions.

\section{Conventional E-Learning towards Cloud-Based E-Learning}

Based on [8] which is also illustrated in Figure 1, the main advantages of the adoption of cloud computing is efficient in terms of cost, this is an interesting point of view that can be adapted to develop e-learning based on cloud computing. Conventional elearning commonly used by the university developed by the university itself (shown in Figure 6) tend to cause lots of problems such as time to designing e-learning systems will be developed, costs for infrastructure, selecting commercial or open source e-learning platform, the cost to hire professional staff to maintain and upgrade the system of e-learning, and so on. This process is more likely need more time.

By introducing cloud computing adopted by e-learning, as shown in Figure 6, institutions can use a single e-learning based on the cloud provided by a cloud provider of e-learning. This model can reduce the initial costs incurred by the institution for the implementation of e-learning by using cloud computing services, because institutions do not need to pay for the purchase of infrastructure, both in terms of procurement of servers and storage. With cloud computing, as an institution of the client can rent the infrastructure to cloud computing service providers [7]. Likewise with the human resources for the development stage, the cloud environment of e-learning has been provided by the cloud service provider, as well as maintenance of the e-learning [9].

The paradigm shift in the implementation of e-learning is an innovation that can help any institution in implementing e-learning. In general, the implementation conventional e-learning, e-learning web-based design, system development and maintenance as well as by internal governance institutions [10]. It had a lot of problems, both in terms of flexibility, scalability, and accessibility [5] [7] [11]. According to [12] are discussed in [3], one of the main important features that can be presented in the use of e-learning in the cloud is scalability, which allows virtualization provide infrastructure layer provided by the cloud service provider. Virtualization helps solve the problem of the physical barriers that are generally inherent in the lack of resources and infrastructure to automate the management of these resources as if they were a single entity through hypervisor technologies such as virtual machine (VM). 

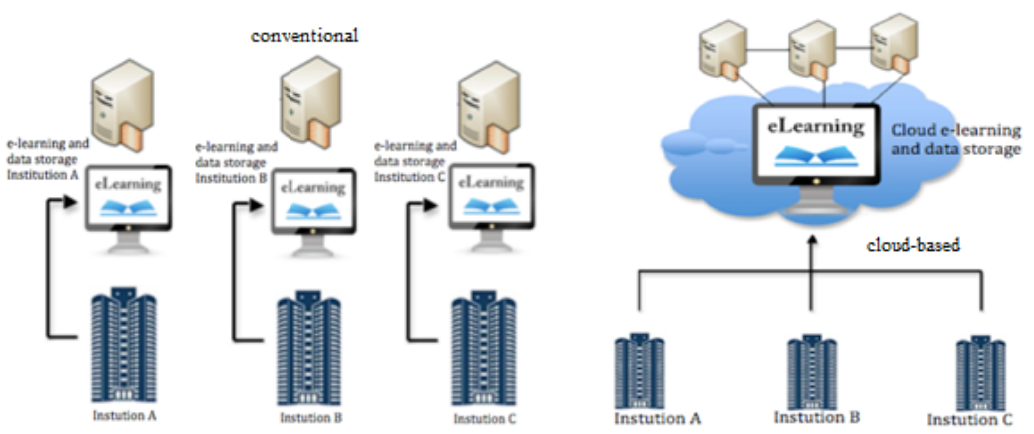

Fig. 3. Conventional E-Learning Towards Cloud-Based E-Learning

\section{$6 \quad$ Expected Benefits}

The expected advantages by adopting the cloud-based e-learning model are as follows: (1) Large capacity, this criteria could adress on-demand self service characteristic from could computing. Large scale storage in cloud environments provide advantages to the consumer to determine the storage capacity they intend to use that are adjusted to their needs and capabilities of the institution as a consumer of cloud-based e-learning; (2) Short implementation process, by using cloud-based e-learning services, educational instition could minimize their expenditure to develop the e-learning system and shorten the implementation process because the e-learning system already developed and maintained by the cloud e-learning provider; (3) High Availability, by utilizing large storage and high performance computing power, cloud e-learning could provide a high quality of service. This may happened because of the support system that supports cloud e-learning can detect the node failure and can be immediately diverted to another node. Besides the high level of availabilitas system, with a large storage so that many learning resources can be gathered by combining learning resources from any educational institution who joined the cloud e-learning by integrating the learning resources with integrated database system mechanism; (4) Just in time learning, using cloud computing for e-learning system encourages the use of e-learning more dynamic with added services through mobile devices, of course, by adding an integrated mobile learning services in a cloud-based e-learning. With adding mobile learning features, cloud-based e-learning become more powerful so the users could access the learning material any-time and any-where and just utilize their mobile devices like smartphones as an example.

\section{$7 \quad$ Conclusion and Future Work}

This paper proposes a model of e-learning based on cloud computing. Implementation of e-learning is now generally constructed separately by each institution, the implementation of such this conventional models is costly, because it takes the cost for provision of infrastructure, systems development, and hiring IT staff to maintain and 
enhance e-learning systems. Cloud computing as one of the technologies used currently rife in the IT world can be utilized for the implementation of e-learning. With the implementation of e-learning in a cloud environment, educational institutions no longer have to pay for the provision of infrastructure because infrastructure has been provided by the cloud service provider of e-learning and agencies that wish to use it only pay according to the usage by the institution. For the cost of developing elearning systems and staff to maintain and enhance e-learning systems, cloud service providers also provide service for it, and educational institutions will only pay for the services they already use.

In this paper we propose the architecture that consists of five layers, namely : (1) infrastructure layer; (2) platform layer; (3) application layer; (4) access layer; and (5) user layer. The first three layers are the basic of cloud services, then we added two additional layers, namely access layer and user layer. Access layer consists of a variety of devices used to access the cloud e-learning, whether in the form of notebooks, PCs, Smartphones, Tablets, etc. At the users layer consists of various educational institutions that will use cloud e-learning. As the implementation of the proposed architecture, authors have developed a prototype of a cloud-based e-learning is being piloted at three higher education institutions that are used in teaching and learning, and in the future we will perform an evaluation of the use of cloud-based e-learning.

\section{References}

1. Tzeng, G.H., Chiang, C.H., Li, C.W.: Evaluating intertwined effects in e-learning programs: A novel hybrid MCDM model based on factor analysis and DEMATEL. Expert Systems with Applications 32(4), 1028-1044 (2007)

2. Chuang, S., Chang, K., Sung, T.: The Cost Effective Structure For Designing Hybrid Cloud Based Enterprise E-Learning Platform. In: IEEE CCIS (2011)

3. Dong, B., et al.: An E-learning Ecosystem Based on Cloud Computing Infrastructure. IEEE (2009)

4. Chandran, D., Kempegowda, S.: Hybrid E-Learning Platform Based On Cloud Architecture Model: A Proposal. IEEE (2010)

5. Phankokkruad, M.: Implement of Cloud Computing For E-Learning System. In: IEEE ICCIS (2012)

6. Yan, S., et al.: Infrastucture Management Of Hybrid Cloud For Enterprise Users. IEEE (2011)

7. Ghazizadeh, A.: Cloud Computing Benefits And Architecture In E-Learning. IEEE (2012)

8. Carroll, M., Merwe, A., Kotzé, P.: Secure Cloud Computing Benefits, Risks and Controls. IEEE (2011)

9. Pocatilu, P.: Cloud Computing Benefits for E-learning Solutions, Romania, Bucharest. Academy of Economic Studies (2010)

10. Méndez, J.A., González, E.J.: Implementing Motivational Features in Reactive Blended Learning: Application to an Introductory Control Engineering Course. IEEE (2011)

11. Masud, M.A.H., Huang, X.: An E-learning System Architecture based on Cloud Computing. IEEE (2012)

12. Jones, M.T.: Cloud computing and storage with OpenStack: Discover the benefits of using the open source OpenStack IaaS cloud platform. In: Developer Works (2012) 
13. Vishwakarma, A.K., Narayanan, A.E.: E-Iearning as a Service: A New Era for Academic Cloud Approach. In: ISI International Conference on Recent Advances in Information Technology. IEEE (2012)

14. Nuh, M.: Arahan Mendikbud pada Rembug Nasional Pendidikan dan Kebudayaan (2012) (retrieved)

15. Sailah, I.: Kebijakan Direktorat Pendidikan Tinggi Tentang Program Studi. (2012) (retrieved), http://telaga.cs.ui.ac.id/ heru/archives/sarasehanAptikom2

16. Gierlowski, Nowicki: Loosely-Tied Distributed Architecture for Highly Scalable ELearning System. In: Soomro, S. (ed.) E-learning Experiences and Future. InTech. (2010) ISBN: 978-953-307-092-6

17. Grewal, A., Rai, S., Phillips, R., Fung, C.C.: The E-Learning Lifecycle and its Services: The Web Services Approach. In: Proceedings of the Second International Conference on eLearning for Knowledge-Based Society, vol. 8, pp. 4.1-4.8 (2005)

18. Pankratius, Sandel, O., Stucky, W.: Retrieving Content With Agents In Web Service eLearning Systems. In: Symposium on Professional Practice in AI, First IFIP Conference on Artificial Intelligence Applications and Innovations (ALAI), pp. 91-100 (2004)

19. Xu, Z., Yin, Z.G., Saddik, A.E.: A Web Services Oriented Framework for Dynamic ELeaming Systems. In: IEEE CCECE- CCGEI 2003, Montreal (2003)

20. Arthana, I.K.: Multi-channel Access pada Sistem Temu Kembali Multimedia. Fasilkom UI, Depok (2011)

21. Mell, P., Grance, T.: The NIST Definition of Cloud Computing. NIST, Gaithersburg (2011) 